\title{
Progress towards an optically powered cryobot
}

\author{
W.C. STONE, B. HOGAN, V. SIEGEL, S. LELIEVRE, C. FLESHER \\ Stone Aerospace, Del Valle, TX, USA \\ E-mail: billstone@stoneaerospace.com
}

\begin{abstract}
VALKYRIE (Very-deep Autonomous Laser-powered Kilowatt-class Yo-yoing Robotic Ice Explorer) is a NASA-funded project to develop key technologies for an autonomous ice penetrator, or cryobot, capable of delivering science payloads through outer planet ice caps and terrestrial glaciers. This 4 year effort will produce a cylindrical cryobot prototype $280 \mathrm{~cm}$ in length and $25 \mathrm{~cm}$ in diameter. One novel element of VALKYRIE's design is the use of a high-energy laser as the primary power source. $1070 \mathrm{~nm}$ laser light is transmitted at $5 \mathrm{~kW}$ from a surface-based laser and injected into a customdesigned optical waveguide that is spooled out from the descending cryobot. Light exits the downstream end of the fiber, travels through diverging optics, and strikes an anodized aluminum beam dump, which channels thermal power to hot-water jets that melt the descent hole. Some beam energy is converted to electricity via photovoltaic cells, for running on-board electronics and jet pumps. Since the vehicle can be sterilized prior to deployment, and forward contamination is minimized as the melt path refreezes behind the cryobot, expansions on VALKYRIE concepts may enable cleaner access to deep subglacial lakes. This paper focuses on laser delivery and beam dump thermal design.
\end{abstract}

KEYWORDS: ice engineering, subglacial lakes

\section{INTRODUCTION}

Robotic science missions to the subsurface oceans of Europa and Enceladus, as well as deep investigations into the Martian ice cap, require a smart, high-power science payload delivery mechanism that is capable of penetrating large distances through ice. NASA's Jet Propulsion Laboratory (JPL) conducted seminal work in the design of such a cryobot in the late 1990s (Zimmerman and others, 2001). The JPL cryobot measured $15 \mathrm{~cm}$ in diameter and $100 \mathrm{~cm}$ in length and was designed to test the hypothesis that a radiothermal isotope source $\left(\mathrm{Pu}^{238}\right)$ could be used to create a functional ice penetrator. That research ended in 2002, having successfully demonstrated that a $1 \mathrm{~kW}$ heat source would be sufficient to initiate and sustain motion of the a small-diameter vehicle through ice. The cessation of this work left many crucial questions unanswered, which we discuss below.

\section{Delivery through deep ice caps}

How can realistic planetary science sub-payloads be delivered through deep ice caps? In a Europa mission, the payload would be a relatively large nuclear-powered autonomous underwater vehicle (AUV) of the class needed for long-range exploration and biological searches in the Europan ocean (Stone and others, 2007, 2010; Gulati and others, 2010). Our estimates for the diameter of a flagship mission cryobot range from 1.5 to $2.0 \mathrm{~m}$. The power required to melt ice for a given descent rate is proportional to the square of the vehicle diameter, so the delivery of large amounts of thermal power to the vehicle is necessary for a successful mission. In this sense, there have been no dramatic improvements in field-deployable cryobot architecture since the Philberth probe of the 1960s (Philberth, 1962), since all designs have been electrically powered externally. Not only is this paradigm divergent from the nature of the power supply to be used on the flight vehicle, there is also an inherent limit to the range at which electrical power can be delivered effectively to an autonomous vehicle due to considerations of arc-over in the face of extremely high hydrostatic compression of insulator sleeves over adjacent wire wraps. Conversely, an Advanced Stirling Radioisotope Generator (ASRG) heat source is insufficient for conducting the cryobot-conveyed science missions described above. The next step-up is a compact fissionbased Systems Nuclear Auxiliary Power (SNAP) or Topazclass reactor operating in the mid-power range (20-100 kW).

\section{Vehicle thermal management}

How can we address the problem of dynamic thermal management of a vehicle that is powered predominantly by a thermal source, from which only limited local electrical power is required? The power source for any cryobot flight mission, whether radioisotopic or fission-generated, is thermal. It is wasteful to convert raw thermal power to electrical power, only to then use that power to transfer heat or cooling to some other location on the vehicle. The problem requires an actively controlled thermodynamic balance system that distributes heat where it is needed, or extracts it from where it is not, and only generates what is essential for the operation of inherently electronic devices.

\section{Obstacle detection and avoidance}

How do we implement active and effective long- and shortrange obstacle detection in a cluttered and stratified ice cap? Moons like Europa have certainly been impacted by countless objects over the eons, and debris likely exists within the ice cap. This requires a means to generate full three-dimensional situational awareness of both large objects at long range (on the order of a kilometer away) and small centimeter-sized objects within intermediate ranges (tens to hundreds of meters) so that an optimal descent trajectory can be planned. It also means that the cryobot must be able to actively deviate from a vertical descent path.

\section{Dealing with sediment build-up}

Ice accumulates airborne dust on Mars and Earth, and similar material will be deposited during asteroid impacts 


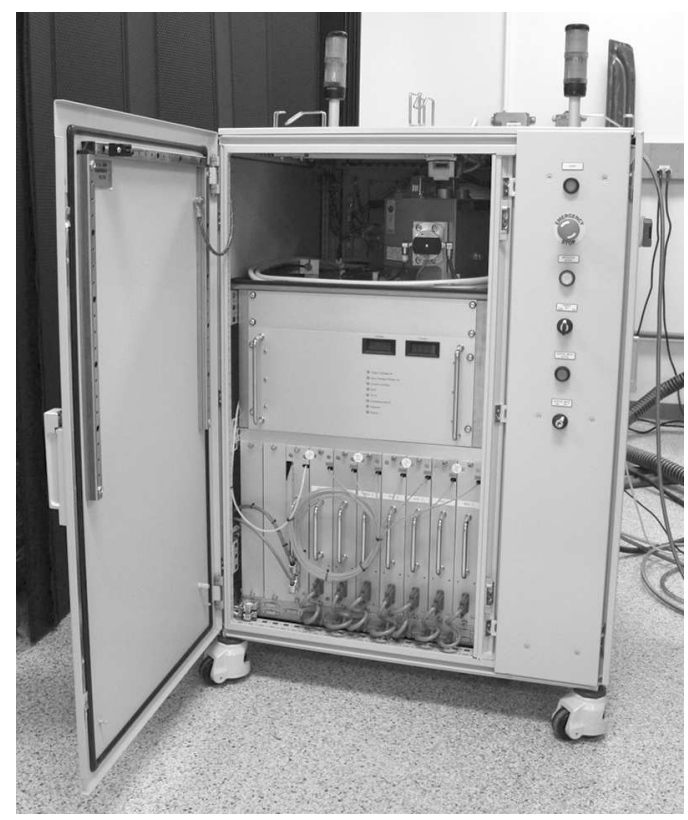

Fig. 1. VALKYRIE fiber laser.

with the outer planet icy moons. As the cryobot melts ice, sediment will be released and will accumulate ahead of the probe. This problem, known for some time in Antarctic research circles, has only been bypassed by brute force and megawatt-level hot-water drilling techniques (e.g. Engelhardt and others, 2000). Limited success was obtained in a laboratory setting using hot-water jetting with the JPL cryobot (Zimmerman and others, 2001). The extension of these concepts to a functional vehicle capable of penetrating both downward and upwards in an ice cap many kilometers thick remains to be investigated.

\section{Sample return}

To date, sample return not been discussed in the literature since it has been assumed that any cryobot mission would involve a one-way descent and that data would be relayed back to a surface lander. A capability for sample return needs to be demonstrated.

\section{VALKYRIE: functional approach}

VALKYRIE was designed to address all of these issues and to field-test the solutions. We emulate the power of a small nuclear thermal reactor through an environmentally acceptable surrogate: a high-power surface-based continuouswave (CW) laser. The laser beam is injected into an optical waveguide, or fiber, which is deployed from an on-board spooler in the aft-end of the vehicle as the cryobot descends. Upon emerging from the downstream terminus of the fiber, the beam is channeled and expanded into an anodized aluminum beam dump and heat-exchanger assembly at the nose of the cryobot. A portion of the optical power delivered to the beam dump is converted to electricity by arrays of photovoltaic cells lining portions of the dump. This electricity powers on-board electronics and hot-water pump jets. An end-fire synthetic aperture radar (SAR) images the area ahead of the vehicle for obstacles, and the vehicle is able to selectively use lateral hot-water jets to steer the vehicle in obstacle-avoidance maneuvers.

VALKYRIE is a multiphase project. In this paper we focus only on two key technologies that have been developed in phase 2: (1) the delivery of laser power via fiber-optic waveguide and (2) the design of the vehicle's beam dump. We present results of testing performed to validate those concepts. Details of the SAR system, sample return concepts, and the on-board astrobiology science payload and science objectives will be presented in later papers.

\section{LABORATORY TESTS OF CRITICAL TECHNOLOGIES High-power laser systems}

VALKYRIE's power source is a multimode CW $1070 \mathrm{~nm}$ diode-pumped ytterbium fiber laser (Fig. 1). In the phase 2 laboratory and initial fieldwork tests we are employing an IPG YLS-5000 laser with a nominal CW output of $5 \mathrm{~kW}$; lasers of this class capable of producing up to $120 \mathrm{~kW}$ are available for developing higher-power cryobots in future phases. Figure 2 shows the anticipated set-up for the VALKYRIE phase 2 field campaign. Several high-power optical junction blocks (lower right image in Fig. 2) will be used to modularize the field set-up. Importantly, the power can be increased linearly. This will be significant for thermal management of VALKYRIE. A $5 \mathrm{~kW}$ laser is approximately equivalent to a refrigerator in size and mass. The electrical power conversion efficiency is $35 \%$, which means that $15 \mathrm{~kW}$ of generator power is required to run the laser in a field setting; an additional $10 \mathrm{~kW}$ is required to run auxiliary systems including laser thermal control. While our risk reduction tests will operate at $5 \mathrm{~kW}$, the units can be joined to produce a 50-100 kW system, which will significantly improve descent speed for a realistic size subglacial mission to Antarctica in future project phases. Such power levels are approaching that of a small fission reactor, which might be considered for a Europa AUV mission.

The above-mentioned laser statistics are for current (2013) fiber laser capabilities, but this technology has advanced at a rapid rate and it is likely that in the next few years we will see field-portable systems approaching $100 \mathrm{~kW}$. The theoretical maximum power that can be conveyed by a single fiber is set by the catastrophic selffocusing limit $P_{\text {crit, }}$ which for fused silica fiber is $\sim 4.3 \mathrm{MW}$ (Farrow and others, 2006). These limits far surpass current technology, but may one day be achievable. Importantly, this limit was calculated for a $25 \mu \mathrm{m}$ core fiber, which means that even a small cryobot will be able to receive high levels of power at long ranges, potentially in excess of $40 \mathrm{~km}$. It is important to recognize that, within the power ranges we have investigated during this project, loss is dominated by fiber length, fiber cladding, configuration of materials and fiber bend radius among other factors, but not by the level of power transmitted. Figure 3 shows the consequences of this at the low end of this power scale for a $25 \mathrm{~cm}$ diameter cryobot. As we approach $100 \mathrm{~kW}$, ice penetration times for a $3 \mathrm{~km}$ ice cap can be reduced to a number of days not months. An engineering optimization trade study will be required to balance logistics costs against the benefit of reduced penetration time for subglacial access in remote locations on Earth (e.g. Antarctica). It is our opinion that these power levels will be achievable in the next few years in compact systems and can be made available today by running off-shelf systems in parallel.

\section{Optical power transmission}

There are three fundamental technical questions confronting VALKYRIE: Is it possible to inject a high-power beam into an 


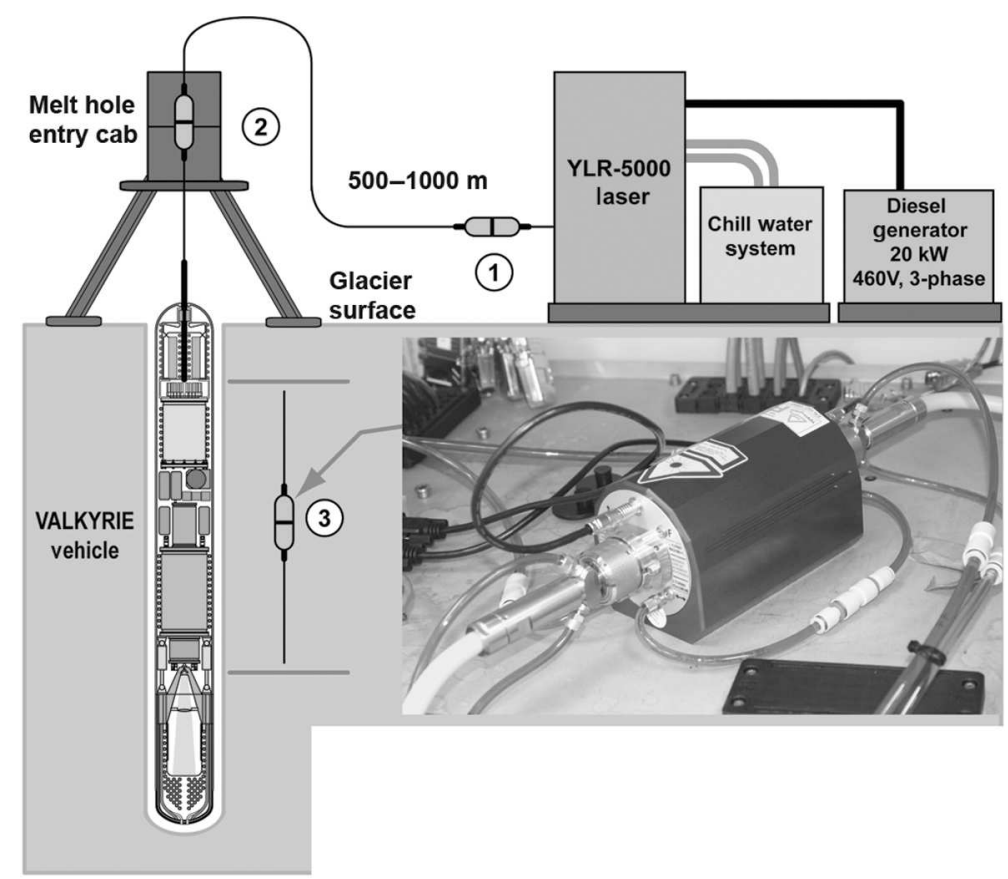

Fig. 2. VALKYRIE field test set-up.

external optical waveguide? Will there be unacceptable power losses over a $3-4 \mathrm{~km}$ penetration distance? Will the bending of the fiber to create an on-board spooler on the vehicle exacerbate power losses?

High-power fiber transmission tests were conducted by Stone Aerospace (SAS) engineers in July 2010. The optical waveguide was a custom-made silica fiber $1050 \mathrm{~m}$ in length with a core diameter of $400 \mu \mathrm{m}$, which was spooled onto a water-cooled polyethylene tray of $1 \mathrm{~m}$ diameter (Fig. 4). The spool diameter was chosen because it exceeds the theoretical threshold for significant power loss due to fiber-bending effects. The power transmission fiber, specified by SAS and manufactured by Polymicro, consisted of a multimode step index pure silica core with fluorine-doped cladding. It had

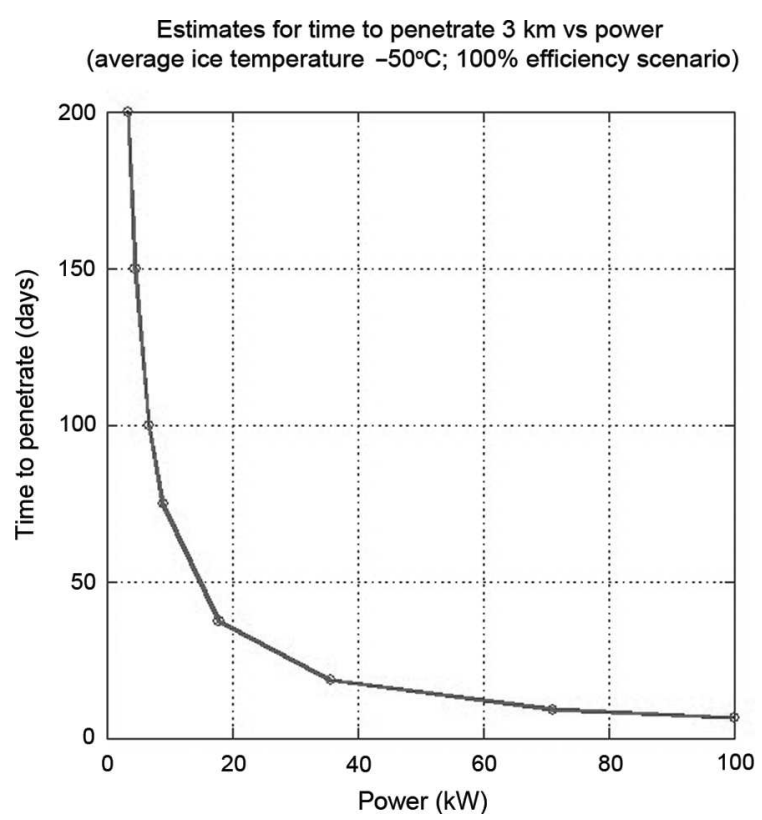

Fig. 3. Mission duration as a function of input power for a $0.25 \mathrm{~m}$ diameter cryobot. the following layer structure: $400 \mu \mathrm{m}$ core diameter, $440 \mu \mathrm{m}$ outer diameter (OD) cladding and $480 \mu \mathrm{m}$ OD polyimide coating (for the prevention of water intrusion). The composite fiber had a numerical aperture (NA) of 0.22.

For these high-power tests we used an IPG $20 \mathrm{~kW}$ multimode fiber laser $(1070 \mathrm{~nm}$, model No. YLS-20000).

The laser was calibrated, using a collimator and a Primes calorimeter, from $40 \mathrm{~W}$ to $20 \mathrm{~kW}$ prior to testing through the optical waveguide. Figure 5 shows the experiment architecture. Connection of modular high-power laser elements requires the use of special connectors in which the fiber is terminated into a fused quartz block within a water-cooled housing. Two connectors can be joined within a beam coupler (Fig. 6), which contains internal optics that expand, collimate and align the beam with the adjacent connector optics. The coupler housing is also water-cooled and contains several sensor interlocks that enable automated shutdown of the laser if the coupler overheats. These interlocks are required because the power levels are sufficient to initiate a fiber 'fuse' in the event of a thermal

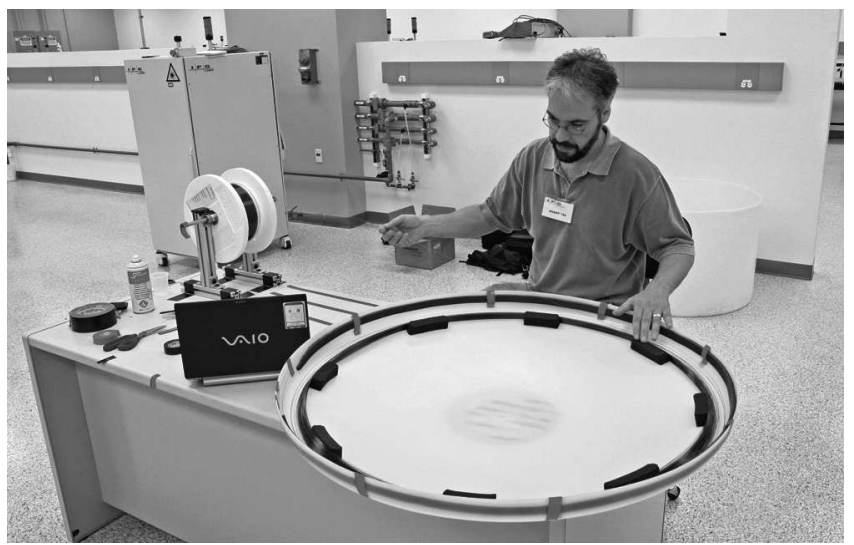

Fig. 4. Preparing $1050 \mathrm{~m}$ of fiber for the initial high-power transmission test. 


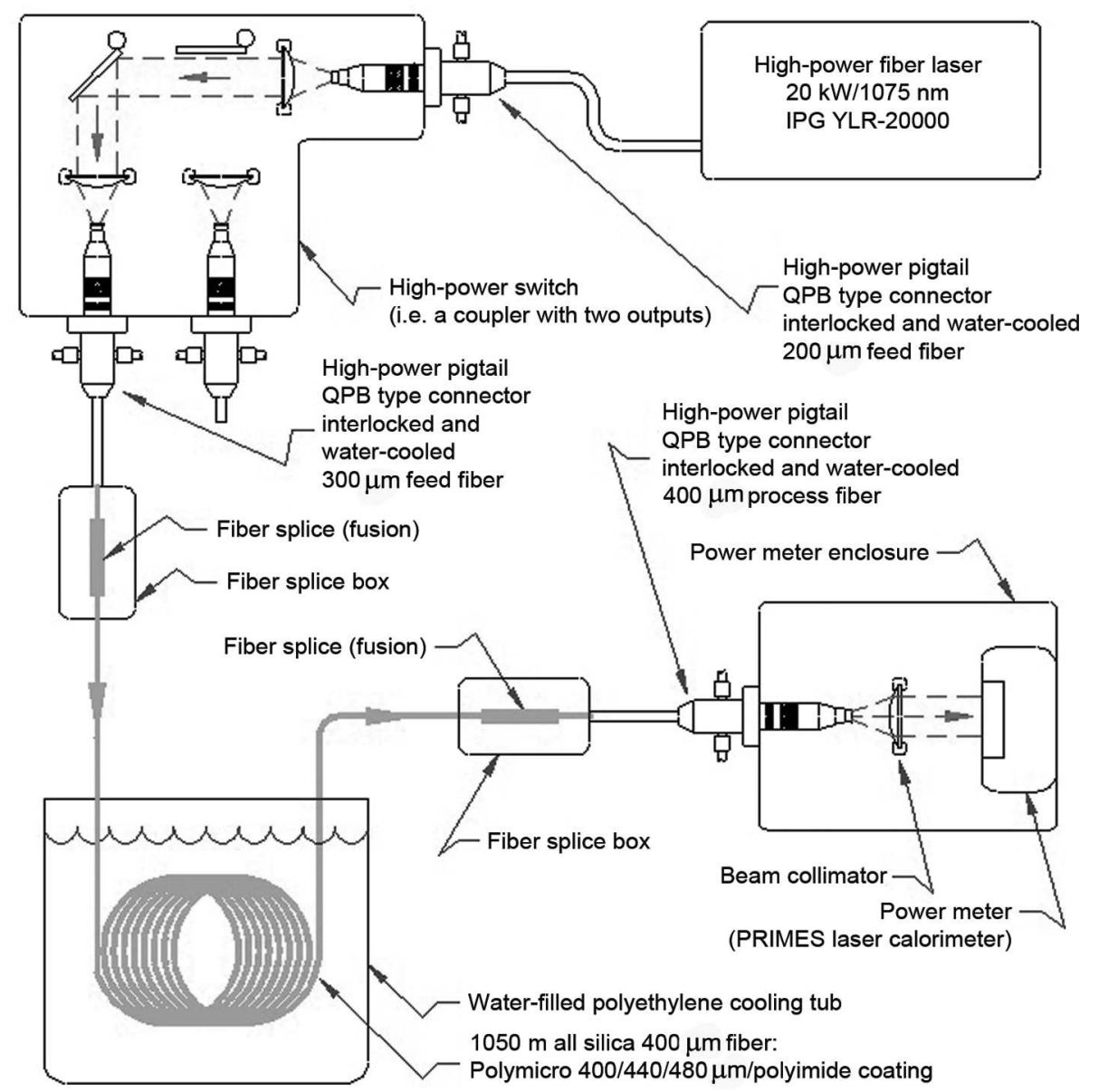

Fig. 5. Schematic of initial high-power transmission test.

runaway in a connector or a defective spot in the fiber that causes it to overheat. In a fuse event, all of the laser energy is dumped into the failure point, which then fuses the silica fiber. The fuse then propagates rapidly back toward the laser.

We used a fusion fiber splicer to join the test fiber coil to the laboratory connectors (Fig. 7). We found that the use of a $300 \mu \mathrm{m}$ core diameter connector fiber led to better coupling of power between the laser and the test coil. The power limit reached in the July 2010 tests was defined by the stray light that made its way into the multilayer cladding, where heat was absorbed and ultimately led to fuse formation. We addressed this issue by fabricating a makeshift cladding light

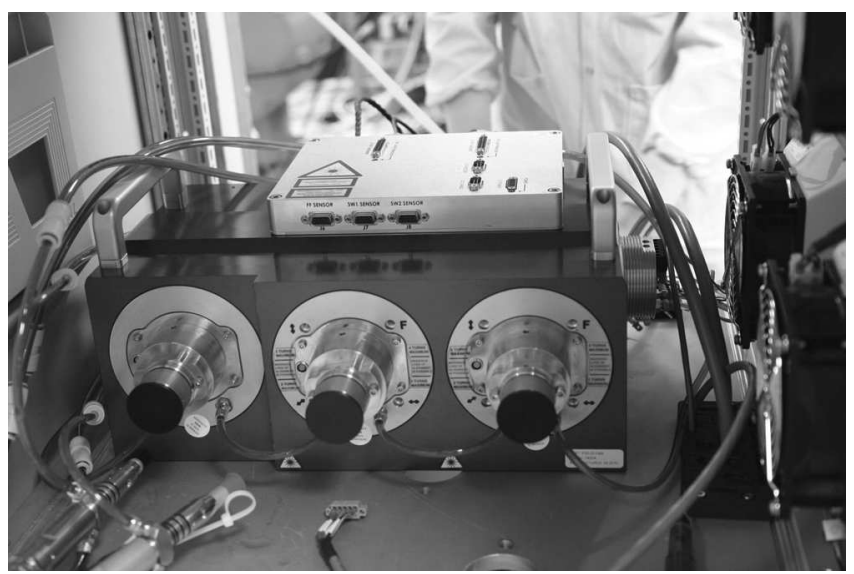

Fig. 6. High-power laser fiber switch. stripper to remove the stray light from the cladding layer. This was accomplished by stripping off the polyimide coating from the fiber in the vicinity of the splice, then mounting to a heat sink and finally covering the splice with an indexmatching gel, which had good thermal conductivity. The index-matching gel allows the light to escape the cladding layer, spill out and be absorbed into the gel and heat-sink assembly. This crude approach eventually led to a burnthrough at the edge of the cladding light stripper at a power level of $11 \mathrm{~kW}$ after several minutes. More effective proprietary splicing techniques were developed in the following 2 years, which effectively mitigated the fiber fuse problem.

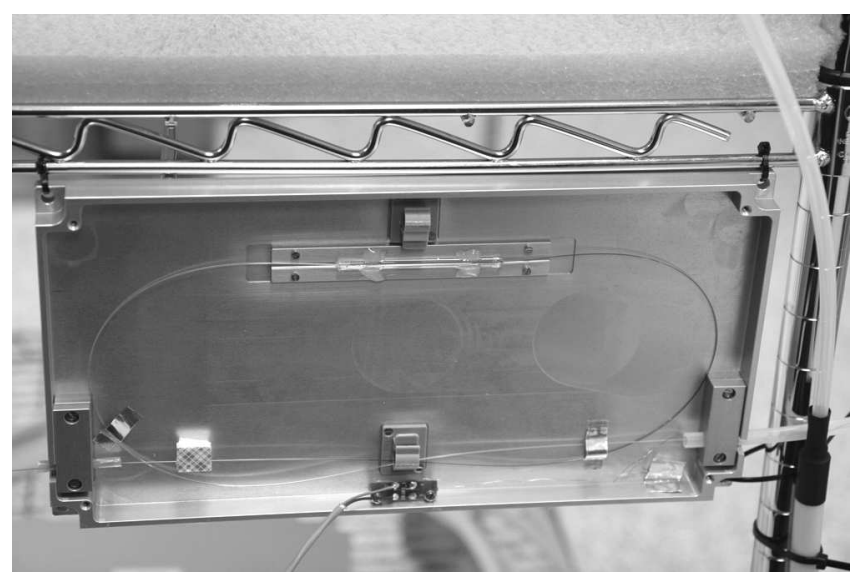

Fig. 7. Fiber splice for initial high-power tests. 
Table 1. Specifications for fiber types used in bend loss tests

\begin{tabular}{lllll}
\hline $\begin{array}{l}\text { Numerical } \\
\text { aperture }\end{array}$ & Core & \multicolumn{2}{l}{ Cladding Coating } & Core material \\
& $\mu \mathrm{m}$ & $\mu \mathrm{m}$ & $\mu \mathrm{m}$ & \\
& & & & \\
\hline 0.22 & 400 & 440 & 480 & Pure silica \\
0.28 & 400 & 440 & 480 & Pure silica \\
0.37 & 400 & 440 & 480 & Germanium-doped silica \\
0.22 & 300 & 330 & 360 & Pure silica \\
0.28 & 300 & 330 & 360 & Pure silica \\
0.37 & 300 & 330 & 360 & Germanium-doped silica \\
0.22 & 200 & 220 & 240 & Pure silica \\
0.28 & 200 & 220 & 240 & Pure silica \\
0.37 & 200 & 220 & 240 & Germanium-doped silica \\
& & & & \\
\hline
\end{tabular}

\section{Initial high-power test results}

Using the set-up described in Figure 4, we cycled laser power from 0 to $10 \mathrm{~kW}$ through the SAS test fiber and measured the output power at the Primes calorimeter. The power loss in the fiber was measured at various laser output power points from $40 \mathrm{~W}$ to $10 \mathrm{~kW}$ (Fig. 8). The fiber transmitted $86.6 \%\left(0.625 \mathrm{db} \mathrm{km}^{-1}\right)$ of the injected laser power at the $10 \mathrm{~kW}$ setting. The laser produced $9.955 \mathrm{~kW}$ at the $10 \mathrm{~kW}$ setting; this was reduced to an estimated $9.589 \mathrm{~kW}$ after splice, switch and coupler losses. The composite estimate for coupler loss was $1.5 \%$ (Fig. 8). The overall loss (at the SAS fiber output end) was very consistent over a range of injected power levels. The loss for the fiber was $13.4 \% \mathrm{~km}^{-1}\left(0.625 \mathrm{db} \mathrm{km}^{-1}\right)$. The theoretical limit for Rayleigh scattering of $1070 \mathrm{~nm}$ light in pure fused silica is $12.0 \% \mathrm{~km}^{-1}\left(0.557 \mathrm{db} \mathrm{km}^{-1}\right)$ (Ghatak and Thyagarajan, 1998). Temperature build-up in the SAS fiber coil (Fig. 9) never exceeded $30^{\circ} \mathrm{C}$, validating our hypothesis that power loss through a fiber spool of large diameter was manageable. As previously mentioned there were significant issues with the fiber splice overheating both due to cladding losses and some unavoidable splice loss.

\section{Bend loss tests}

We are designing the VALKYRIE vehicle so that it can selfdeploy the power tether via an actively cooled on-board fiber spooler. This approach is necessary because meltwater refreezing makes surface-based fiber deployment impossible. There is a lower limit to the spool's diameter due to the increasing power transmission losses, or bend losses, as the fiber bend radius is reduced. Bend loss has both linear and nonlinear components. While significant research has been conducted by industry into bending loss for single-mode communications fiber, limited research has been conducted into bend loss for kilowatt-class multimode lasers. Available research (e.g. Boechat and others, 1991) and modeling predicts a large range of losses for various fiber types and applicable spooler sizes. Testing is underway at SAS to optimize fiber selection for bending loss, vehicle diameter and fiber strength with specific application to VALKYRIE.

Many parameters contribute to bending losses. Some key points from Boechat and others (1991) are as follows:

Bend loss depends on bend radius, increasing nonlinearly as the bend radius is decreased beyond a critical value.

Bend loss depends on fiber radius, increasing nonlinearly as the fiber radius increases, for a given bending radius.

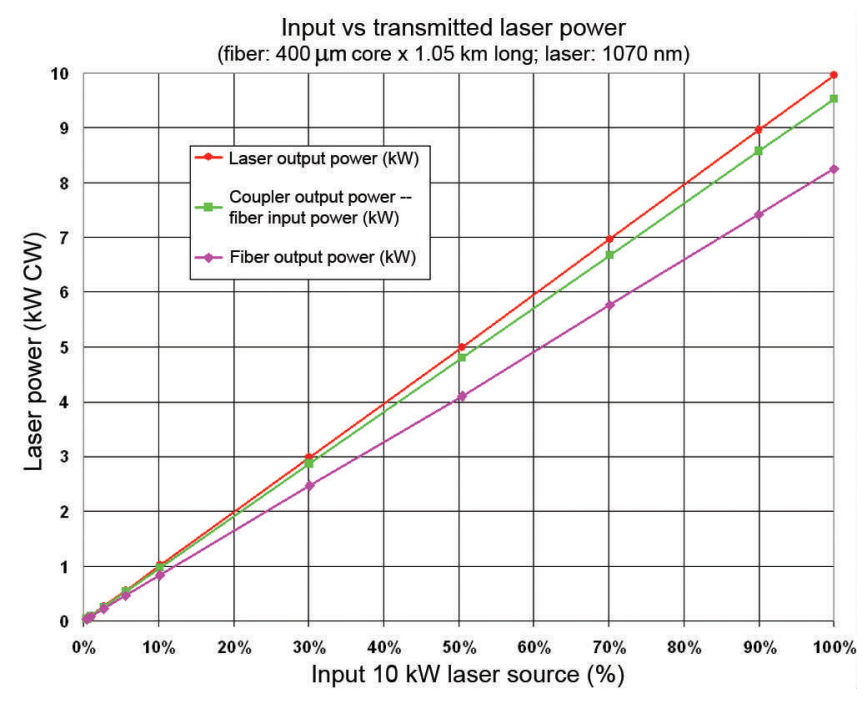

Fig. 8. Transmission power results from first high-power test.

Fiber losses decease nonlinearly as the fiber NA increases.

Bending losses are highly dependent on source conditions, particularly the source NA and source modal distribution.

Underfilling the fiber significantly reduces bend losses. Underfilling occurs when the launch condition of the source has a lower NA than the NA of the long-haul transmission fiber.

Higher-order propagating modes have higher losses, so the mode distribution of the source will affect the bending losses.

We are able to control all of these parameters to some extent, but the most difficult is the modal distribution of the source. Control of the modal distribution requires use of a mode scrambler, which we have yet to incorporate but are currently pursuing.

Our bend loss testing has examined fiber radius, bend radius and fiber NA as variables. An optical fiber is typically constructed with a fiber core, fiber cladding, fiber coating and, often, a fiber jacket. Owing to volume constraints for our application, we have chosen to use unjacketed fibers. Table 1 lists the nine Ceramoptec fibers we have tested. Each fiber is multimode step index and has a polyimide coating. The $0.22 \mathrm{NA}$ fibers have standard fluorine-doped silica cladding, the $0.28 \mathrm{NA}$ fibers have a proprietary

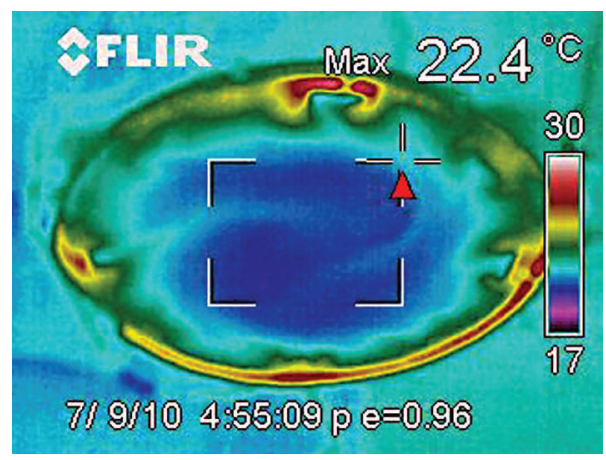

Fig. 9. Thermal camera image showing temperature of the $1050 \mathrm{~m}$ fiber spool at steady-state full power $(10 \mathrm{~kW})$. 


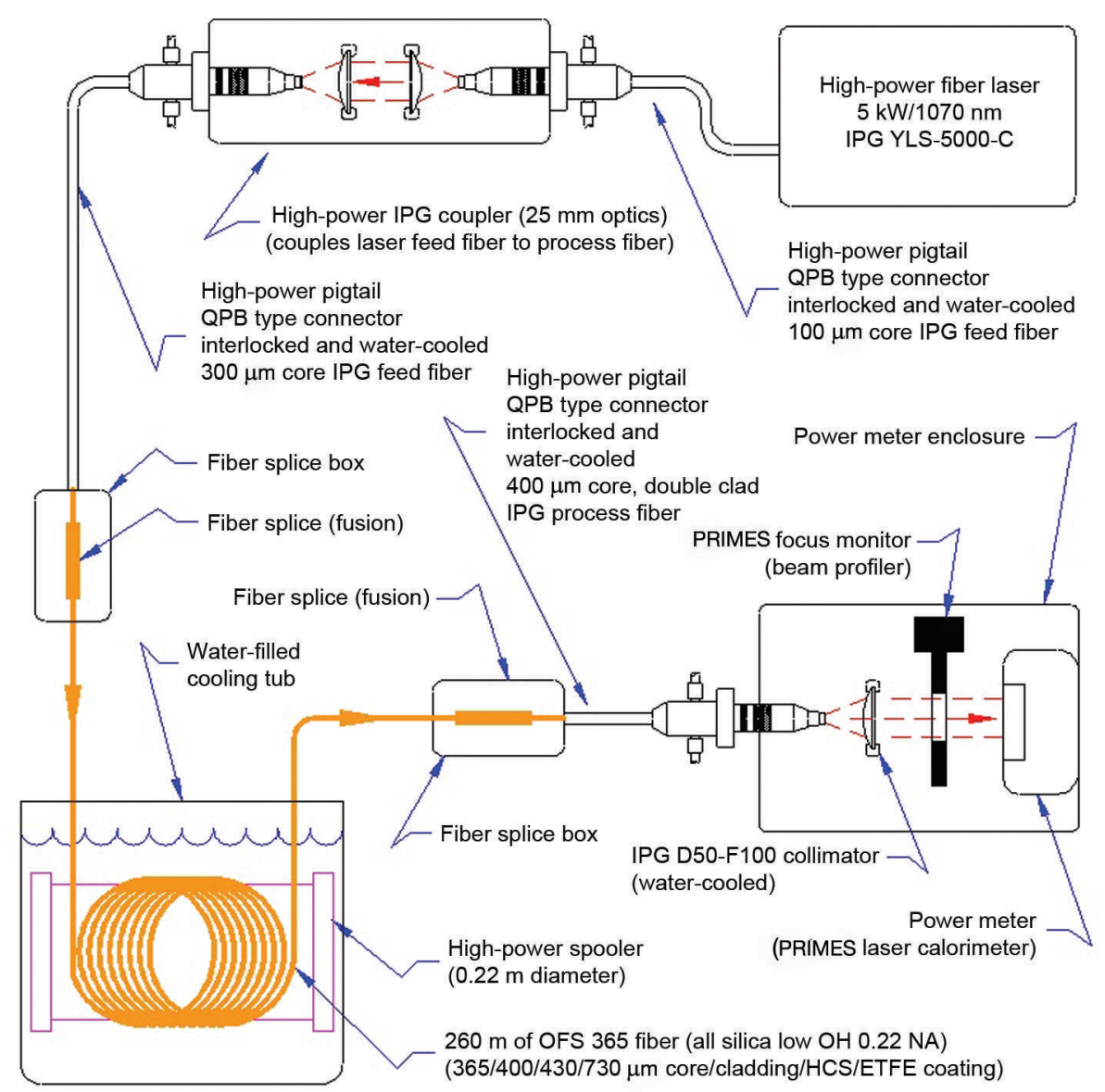

Fig. 10. Set-up diagram for high-power tests of the VALKYRIE fiber spooler.

fluorine-doped silica cladding and the 0.37 NA fibers have a germanium-doped core.

Our conclusion from these tests is that on-board fiber spoolers will need to have a minimum radius of $100 \mathrm{~mm}$ and a fiber NA $>0.28$ in order to keep bend losses low. The same performance levels can be achieved with lower-NA fibers, but with commensurately larger spooler diameters ( $\sim 150 \mathrm{~mm}$ radius). The VALKYRIE spooler is presently being designed with a $100 \mathrm{~mm}$ radius.

\section{Fiber spooler design and testing}

We tested a full-scale spooler mock-up (Fig. 10) to determine realistic fiber transmission loss rates and compared these with predicted results. We also observed the thermal conditions and overall performance of the spooler mock-up. We wound $250 \mathrm{~m}$ of fiber on the spooler, a length

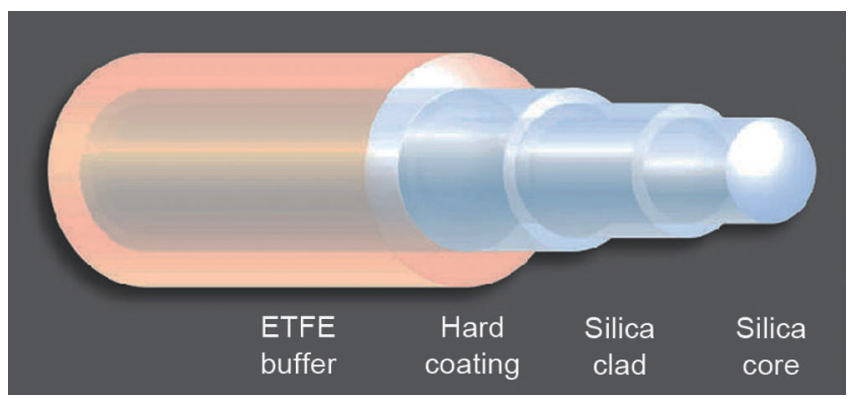

Fig. 11. Schematic of the optical waveguide layers used for the spooler tests. sufficient to enable all field campaign work envisioned in phase 2 . The fiber was fabricated by OFS and had a $365 \mu \mathrm{m}$ pure silica core, with a $400 \mu \mathrm{m}$ doped silica cladding $(\mathrm{NA}=0.22)$ and HCS/ETFE outer coatings (see Fig. 11). The spooler had a diameter of $0.22 \mathrm{~m}$ and a length of $0.5 \mathrm{~m}$, with an aluminum mandrel and Delrin flanges. A layer of Bergquist thermal foam was used to line the spooler surface to enhance heat transfer and reduce fiber micro-bending. For this test series the bare fiber was wound onto the spooler drum by hand (Fig. 12) to ensure that successive wraps did not overlie prior wraps. Micro-bending due to such fiber overlap has been reported to lead to premature failure of telcom fibers, and in a high-power transmission scenario

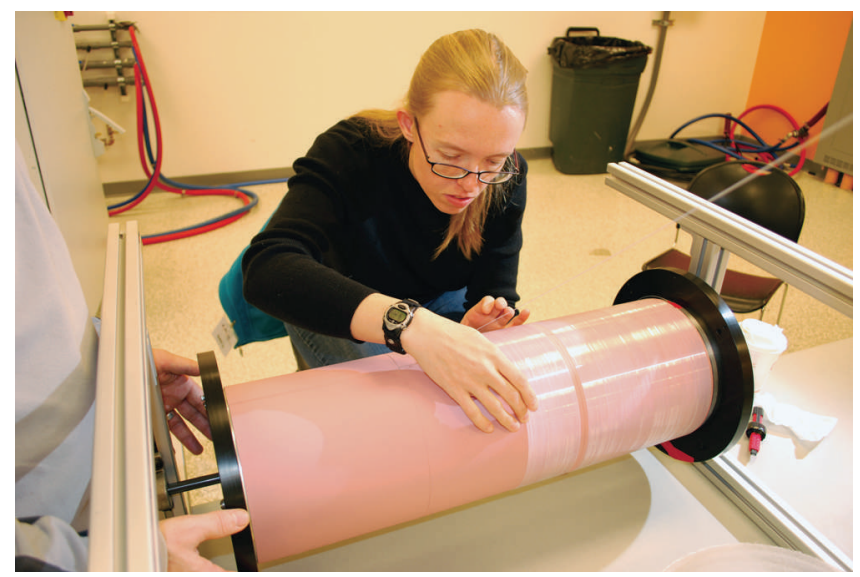

Fig. 12. Winding the VALKYRIE high-power fiber spooler. 


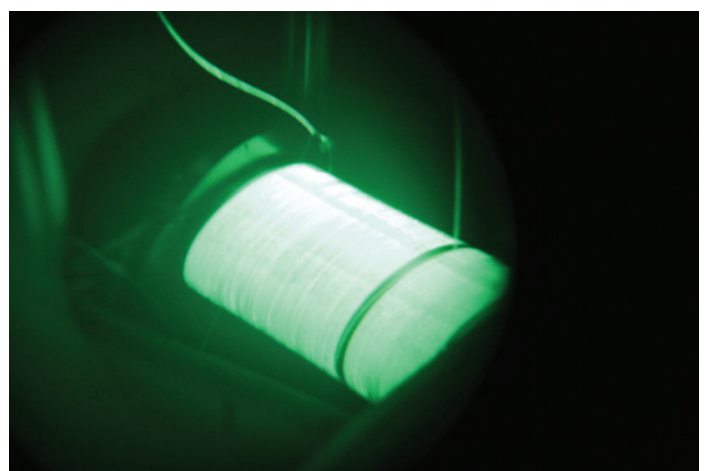

Fig. 13. Infrared image of the VALKYRIE fiber spooler at $5 \mathrm{~kW}$ power input.

fiber overcrossing is to be explicitly avoided. During our previous high-power testing, the fiber splice joints ran quite hot, with one test terminating prematurely because of a fiber-fusing event. We improved the splice technique in subsequent tests and observed only a moderate temperature rise of $\sim 34^{\circ} \mathrm{C}$ at steady state.

In our tests the beam entered the spooler fiber (Fig. 13) with an NA of $\sim 0.10$ (11.5 full angle of divergence), and exited the fiber with an NA of $\sim 0.16$ (18.4 full angle). This divergence is principally a result of mode conversion to higher-order modes due to the bending of the fiber around the spooler. The beam coming from the fiber laser has a low divergence angle. When the beam initially enters the fiber spooler, the fiber is said to be 'underfilled'; the ability of the fiber to guide the beam (fiber NA) is greater than the beam divergence (beam NA), so no power is lost in bending. As the light travels further down the spooled fiber, the continued bending and resulting mode conversion causes increasing beam divergence until it reaches some critical fiber length where the beam divergence exceeds the fiber's ability to guide it; this is where power losses due to bending begin. A fully developed beam exists within the fiber when the system reaches an equilibrium where all additional beam divergence from continued bending is lost, resulting in a steady-state loss operating condition. A critical length of $\sim 500 \mathrm{~m}$ is required for the beam to fully develop within the fiber. For our chosen spool diameter of $0.22 \mathrm{~m}$, these losses should still be well controlled even at $500 \mathrm{~m}$.

We used a collimator of $50 \mathrm{~mm}$ diameter and $100 \mathrm{~mm}$ focal length with internal water cooling. We were able to measure both the power and beam profile output from the fiber. Power was measured with a PRIMES power monitor, and showed much lower bend loss than expected. The initial spooler tests were performed with the spool submerged in water, but the spooler and water bath temperatures never rose significantly above room temperature. We then conducted the same tests with the spooler in air. The steady-state result is shown in Figure 14, a thermal image that indicates a maximum temperature of $36^{\circ} \mathrm{C}$ in the fiber. This is an encouraging result, which provides a margin of safety during initial vehicle power-up for field campaigns.

Figure 15 shows received post-spooler power versus input power from the laser. It is estimated that $\sim 1 \%$ of the initial input power is lost in the fiber coupler, a loss of $\sim 3.6 \%$ of input power comes from the basic fiber loss for $250 \mathrm{~m}$, $\sim 0.1 \%$ of input power loss for the collimator and $\sim 0.1 \%$ loss for the splice, which results in an estimated average value of $\sim 0.4 \%$ bend loss.

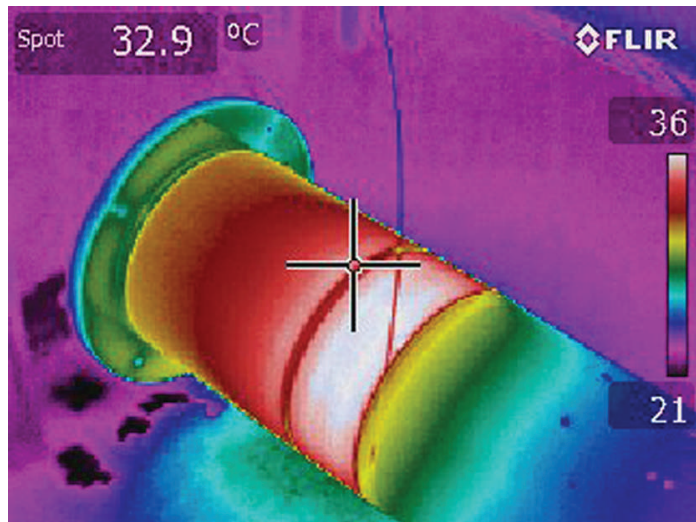

Fig. 14. Thermal camera image showing steady-state temperature distribution on the fiber spooler mock-up at $5 \mathrm{~kW}$ input power.

While we will only be using up to $5 \mathrm{~kW}$ of laser power in the phase 2 vehicle, we extrapolated the predicted field performance of the laser power system we might use in future for higher-power and longer-range versions of VALKYRIE. This extrapolation, based on the high-power $1.05 \mathrm{~km}$ fiber test, fiber bend loss tests and high-power spooler tests, is shown in Figure 16 as power delivered to the vehicle versus vehicle range. The value of $8 \mathrm{~km}$ of fiber was chosen because it is sufficient to reach, and return from, the deepest known subglacial lakes on Earth. At such a range we predict that a $50 \mathrm{~kW}$ surface supply system could deliver $\sim 18 \mathrm{~kW}$ of optical power to the vehicle at maximum spool-out. During the early stages of descent there would be nearly as much power dissipated in the spooler from bend losses as there would be at the melt head. Fluid management systems could use this spooler heat to amplify the heat extracted from the beam dump heat exchanger, leading to faster descent rates.

\section{VEHICLE DESIGN}

\section{Mechanical design}

Figure 17 shows a block diagram for the phase 2 prototype vehicle. The vehicle is currently $25 \mathrm{~cm}$ in diameter and $2.8 \mathrm{~m}$ in length. This cross section makes an Antarctic subglacial lake mission a feasible option for future phases using existing laser technology. The primary power fiber spooler, shown in Figure 17 at the right-hand end of the vehicle, is $0.5 \mathrm{~m}$ in

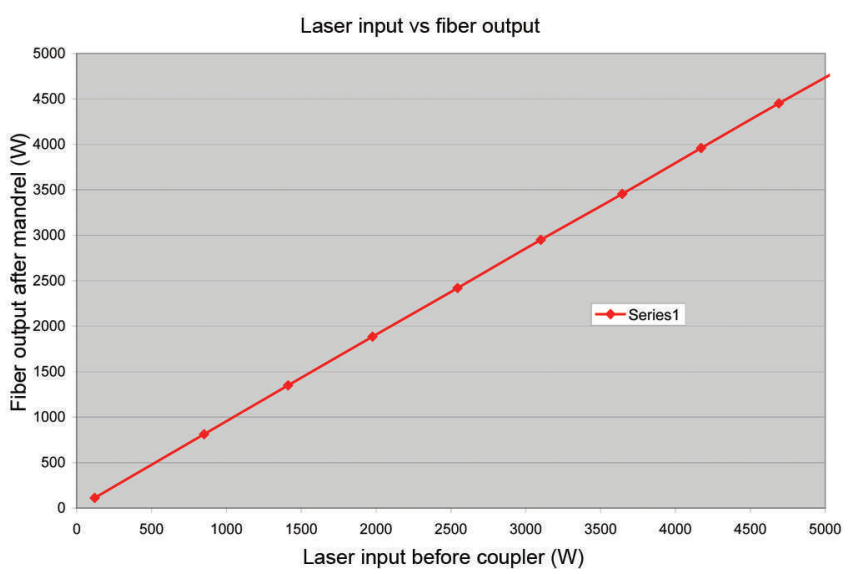

Fig. 15. Power output from the spooler as a function of input power. 


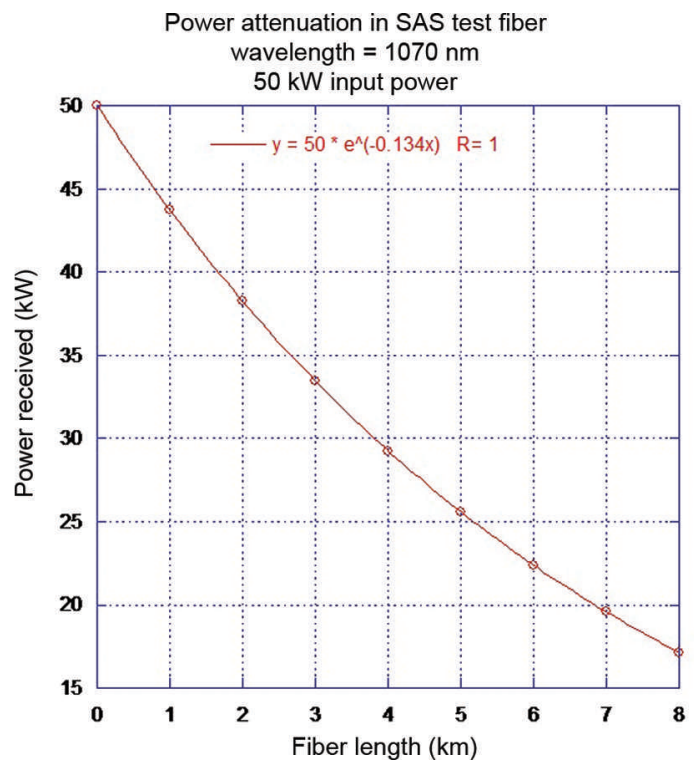

Fig. 16. Theoretical power delivered to VALKYRIE as a function of spooler length for $50 \mathrm{~kW}$ input power.

length, has an OD of $0.22 \mathrm{~m}$ and can accommodate $8 \mathrm{~km}$ of fiber. Communications fiber will be spooled separately. We currently expect to run a QBH fiber pigtail from the fiber spooler, with an optical splice adjacent to the spooler. This in turn plugs into the external pressure hull of the beam dump, where it will guide the beam to the diverging optics assembly. The optics assembly is designed to achieve a uniform beam intensity over the high-temperature photovoltaic (PV) arrays located on the beam dump endplate and side walls.

In 2013, efforts were focused on design completion and the fabrication, integration and testing of a basic cryobot vehicle that could demonstrate critical melt head functions: laser power-to-heat conversion, electrical power generation via laser light on PV cells, and hot-water pumps and jets. Figure 18 shows a section view of the prototype with the following functional sub-systems:

beam dump and pressure housing (at far left of figure)

heat exchangers

hot-water jets, filters and pumps

beam-dispersion optics on-board control computer stack

high-power laser fiber field junction

laser power, communications and liquid-cooling umbilical.

An early decision in the design process involved the separation of the testing of two critical beam dump elements: the heat exchanger and associated beam-dispersion optics and hot-water jet systems, and the power generation system, consisting of a tuned-wavelength heat-tolerant PV array that would see incident laser flux on the order of $10 \mathrm{~W} \mathrm{~cm}^{-2}$.

The beam dump heat exchanger (Fig. 19) must perform several complex tasks within a compact volume. First, it must efficiently collect heat from the laser beam and transfer it to the water routed through the ice-melting jets at the nose of the vehicle. The interior side walls contain scores of forward-facing beveled circular grooves that serve to absorb radiant energy and prevent back-reflection towards the beam-dispersion optics. A non-off-gassing 'optical black' ceramic coating was anodized onto the metal to further enhance heat absorption and minimize reflection. Heat transfer is maximized through the use of a microchannel heat exchanger consisting of hundreds of small vertical channels that transfer the returning meltwater through the hot side walls. Diaphragm pumps, discussed below, then pump the heated water through larger channels to reach the nose-mounted melting and turning jet nozzles. Switchable piping enables the vehicle to channel hot water selectively to turning jets or to direct descent jets. The beam dump must also accommodate electrical sensing lines between the vehicle's nose and on-board computer, and serve as the physical interface to the SAR antennas.

The forward end of the beam dump radiates heat into the side walls through the use of an infrared reflector (Fig. 20). The back side of the reflector cap (Fig. 21) contains a series of planar heat-exchanger channels that serve to cool the reflector and, in later designs, will cool the PV array. A final nose-cone cap plate (Fig. 22) contains the forward melt jet and cruciform-shaped meltwater return channels that draw water back through the heat exchanger. In the black-colored housing of the heat exchanger, behind the bare aluminum front caps in Figure 22, two of the later turning water jets can be seen mounted in the black anodized cone.

The rear of the beam dump (Fig. 23) is populated with fluid-control systems, including redundant diaphragm pumps for driving the hot-water jets, pre-pump intake filters and overpressure regulators. The final design will include
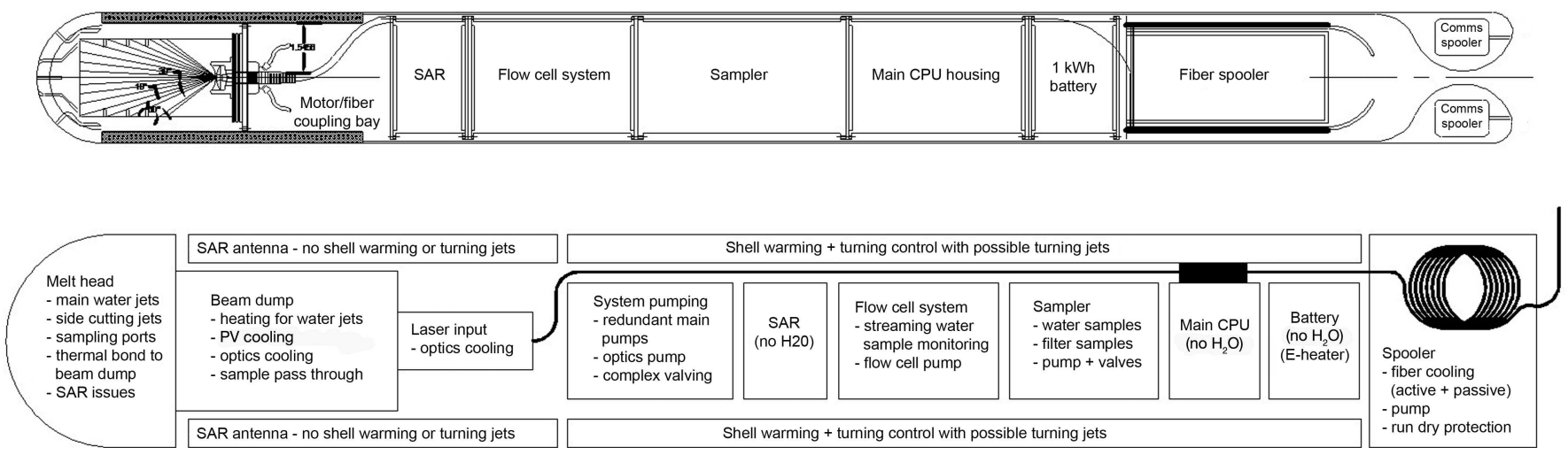

Fig. 17. VALKYRIE functional diagram. 


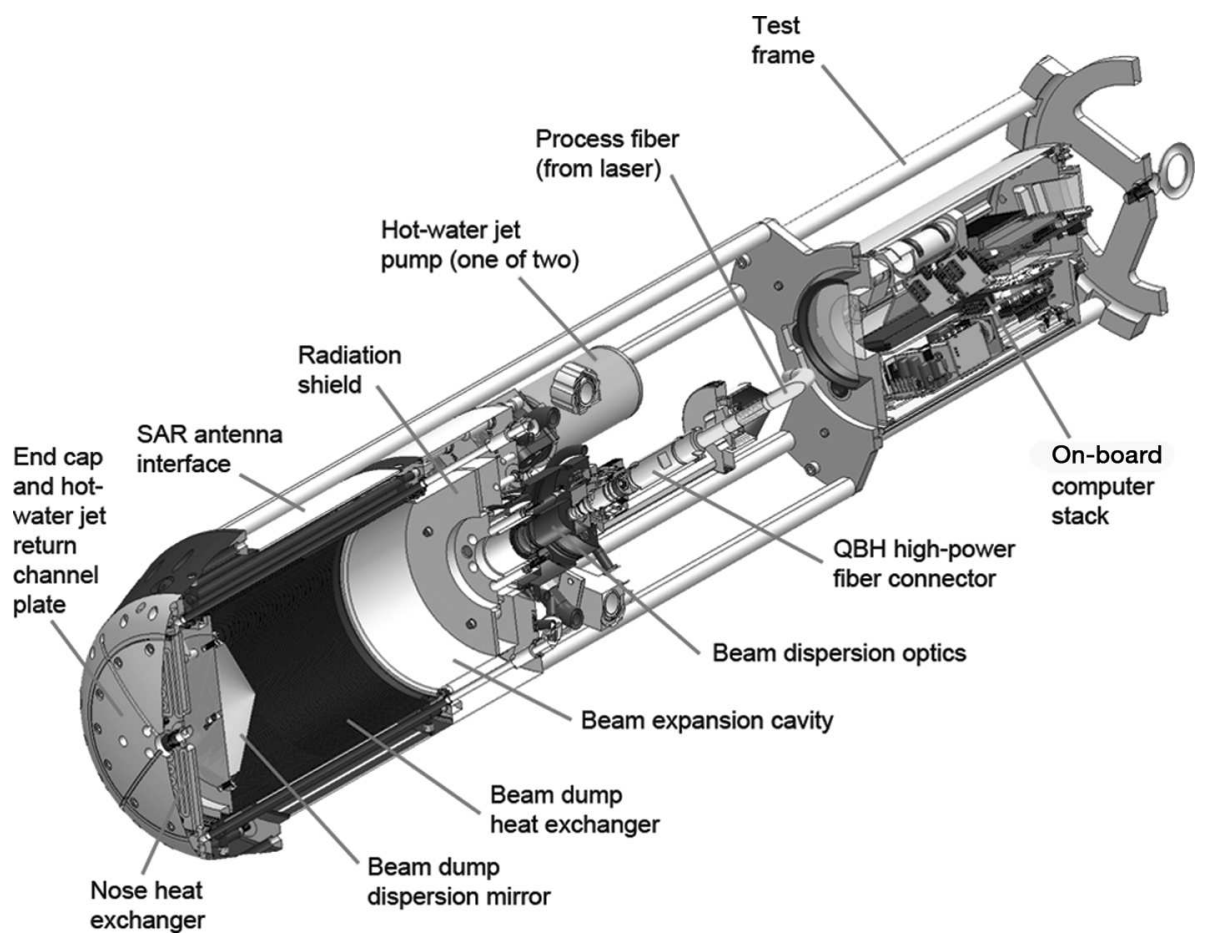

Fig. 18. Solid model section of the initial test prototype for VALKYRIE.

servo-controlled pump output routing valves to steer flow to lateral cutting jets, as required. Shell heaters, required to prevent premature refreeze, are controlled by diverting hot water from the beam dump heat exchanger. Heat for this purpose is also extracted from the fiber spooler heat exchanger (not shown). Figure 24 shows the assembled test vehicle. For simplicity the on-board fiber spooler that will be used in the year 4 field campaign was left out, and an armored fiber connects the melt head optics to the beam dump.

\section{Melt head thermal design}

There are three primary thermal states that can arise on a mission during the operation of the VALKYRIE cryobot: case $A$ - full laser power $(5 \mathrm{~kW})$ and the hot-water jets operating; case $\mathrm{B}$ - full laser power and failure of both water pumps; and case $C$ - full laser power with the jets disabled and water being recirculated through the beam dump heat exchanger with the pumps functioning. Case $\mathrm{C}$ will be implemented while taking water samples from the front of the vehicle.

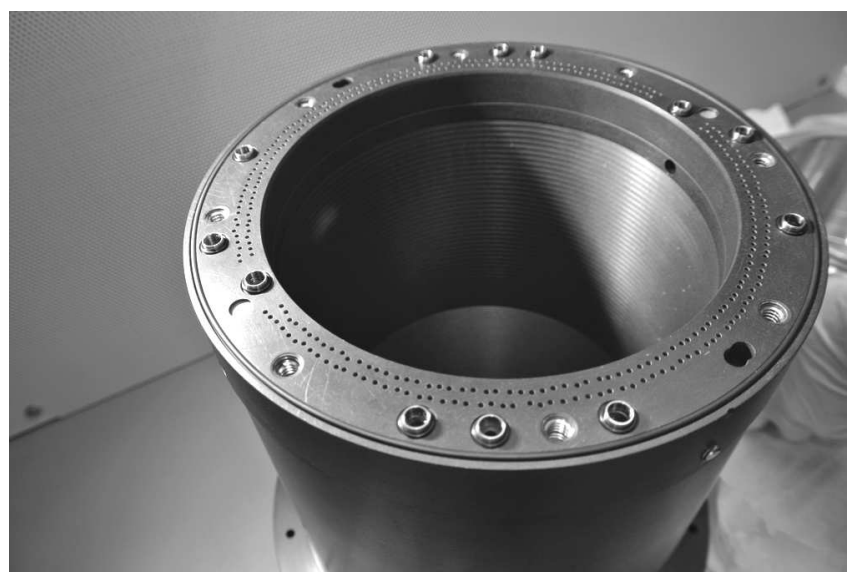

Fig. 19. Rear view of the VALKYRIE beam dump heat exchanger.
We examined each of these states (Figs 25-27) in detail using finite-element analysis thermal modeling procedures (SolidWorks 2012 Flow Professional). Initial design concepts centered on the idea of using beryllium oxide as the beam dump material, but toxicity issues and the complexity of the necessary piping precluded this option on the grounds of fabrication problems. We investigated copper as a material, but it is not available in large billet sizes and similarly cannot be cast with the very complex internal channels required. Ultimately we used a machined block of T6061 T6 aircraft alloy aluminum and a heat-resistant, photon-absorbing,

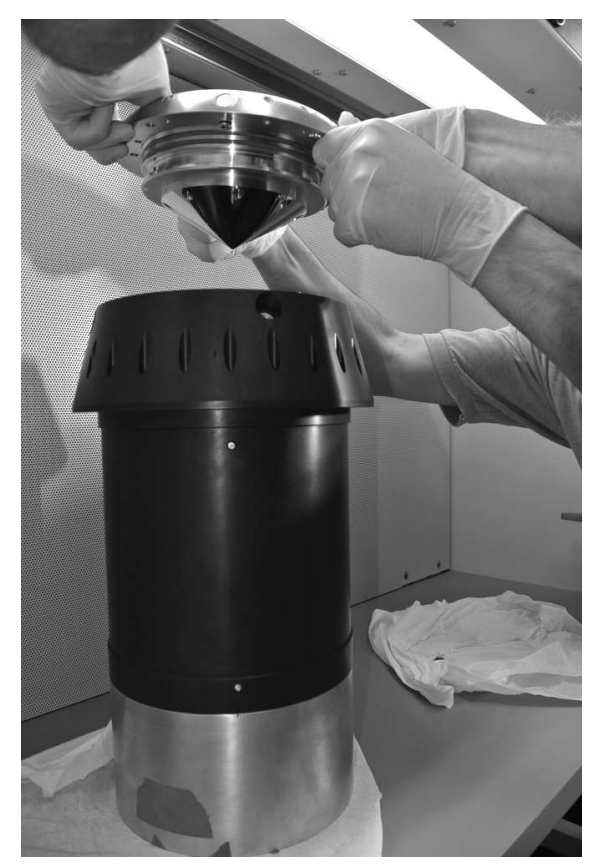

Fig. 20. Mating the mirror assembly to the front of the VALKYRIE beam dump. 


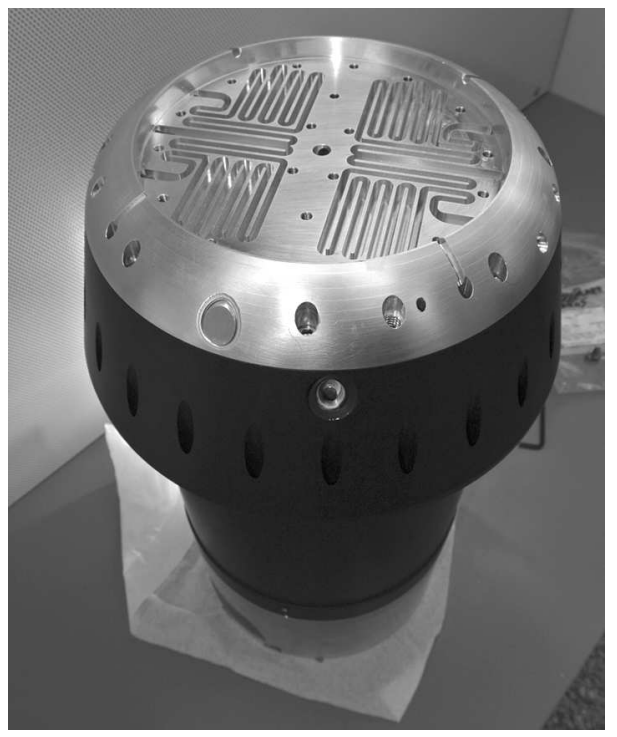

Fig. 21. Cooling channels on the back side of the beam dump for mirror cooling.

non-off-gassing anodized coating. With that basis we began investigating the concept of using wire electrical discharge machining (EDM)-milled microchannels as the basis for the heat exchanger. This option yielded the highest heat flow rate, and EDM machining could bore hundreds of straight small-diameter holes through the $30 \mathrm{~cm}$ length of the beam dump side walls.

Analyses then focused on the spacing, number and diameter of the microchannels. The final microchannel count was $328 \times 1.6 \mathrm{~mm}$ diameter vertically machined holes (Fig. 19). Owing to computation power constraints, simulations were simplified. All simulations were performed using a $0.000322 \mathrm{~K} \mathrm{~m}^{2} \mathrm{~W}^{-1}$ resistive contact between all mating surfaces. A heat flux of $85 \mathrm{~kW} \mathrm{~m}^{-2}$ was applied to the end face of the beam dump, and a heat flux of $35 \mathrm{~kW} \mathrm{~m}^{-2}$ was applied to the cylindrical side walls of the dump. The nose

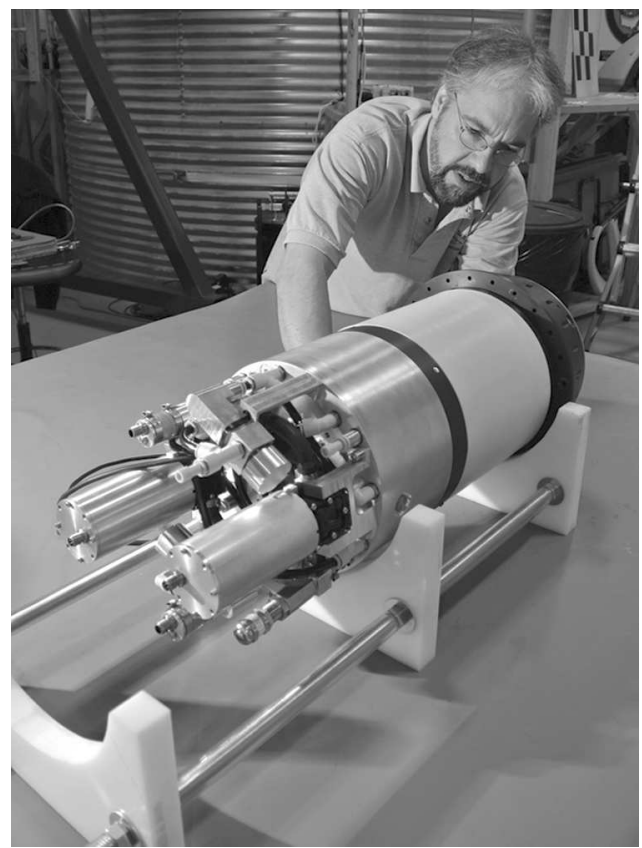

Fig. 23. Hot-water jet pumps, filters and valve assemblies on the back of the beam dump.

was in contact with a simulated body of ice using the same boundary resistance as the rest of the model, while the rear (cylindrical) portion was isolated for the flow modeling. Flowing water was simulated differently for different sections of the vehicle. At the heat exchanger, a small radial section was used in a detailed analysis to determine how much heat was transferred to the flow per unit radial area. Using these results, we then modeled the entire dump and put a flow condition on the outlet of the heat exchanger, which had the water temperature results from the previous detailed heat exchanger section modeling. This simulation of the entire dump also included flow through the nose channels, so that heat picked up was then calculated. All

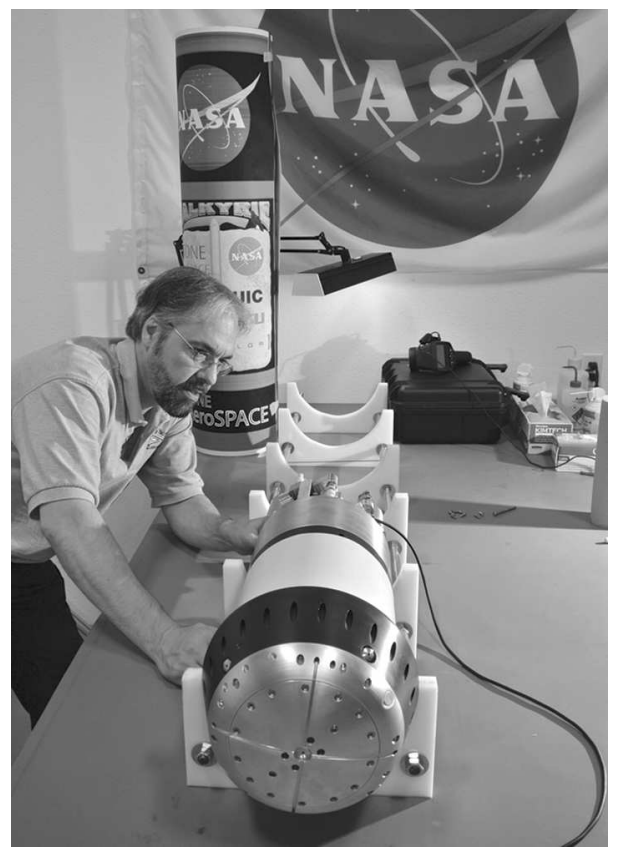

Fig. 22. Assembled VALKYRIE prototype beam dump and melt head.

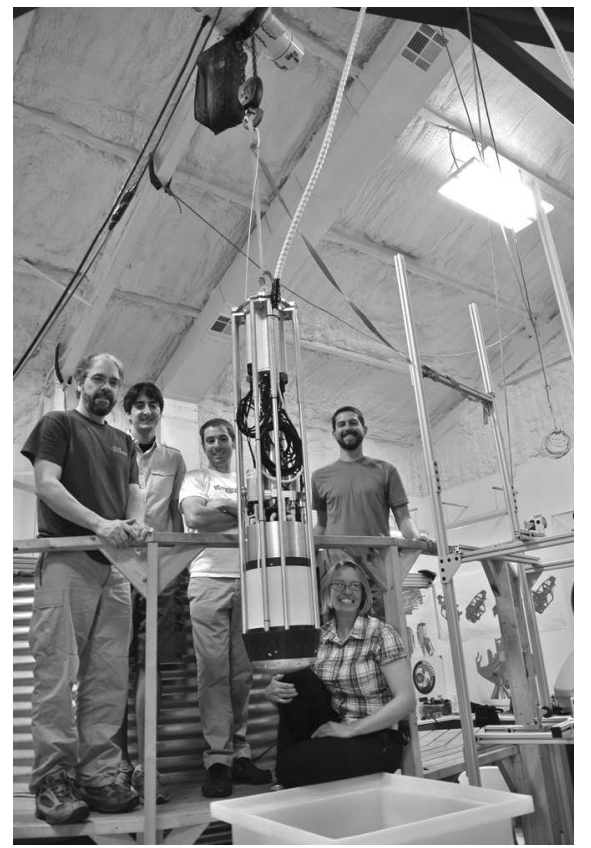

Fig. 24. The assembled laboratory test vehicle. 


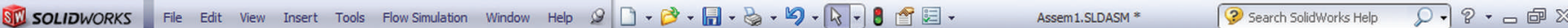

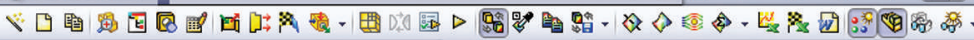

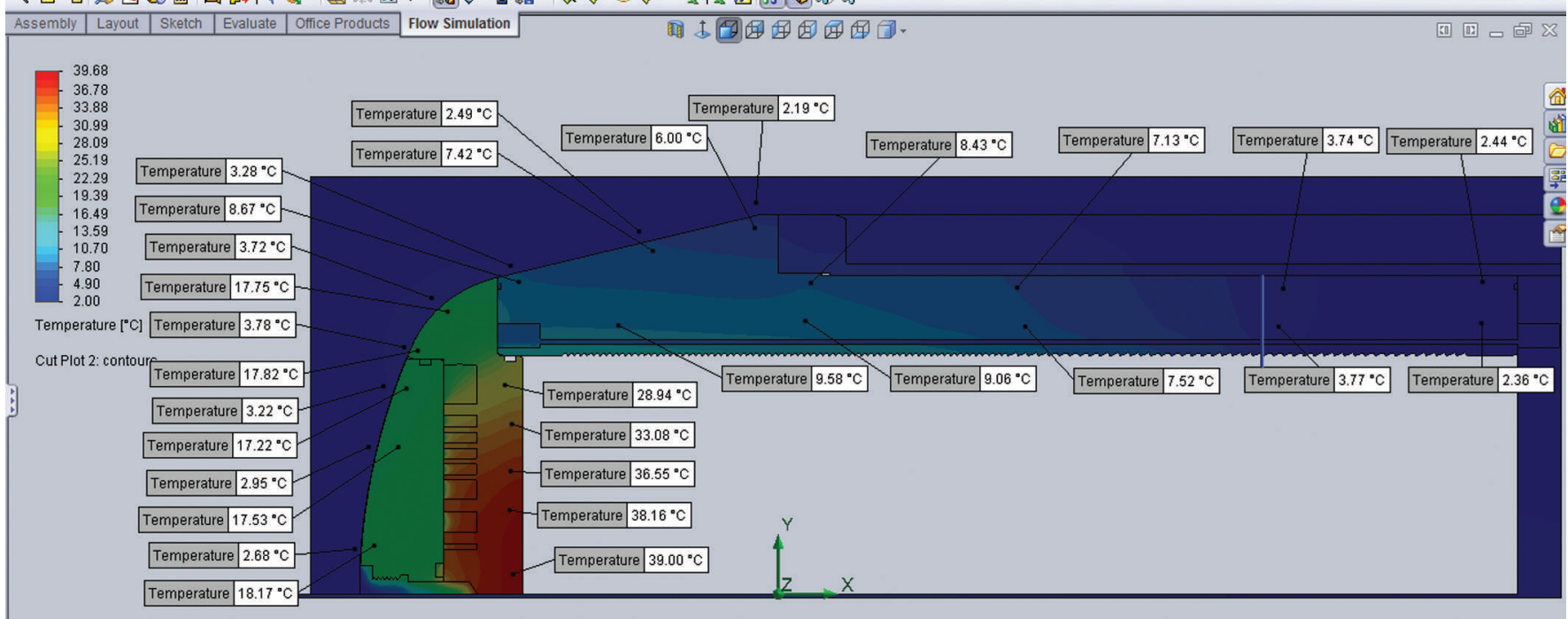

Fig. 25. Steady-state beam dump temperatures at $5 \mathrm{~kW}$ with water jets operating.

simulations were based on a $5 \mathrm{Lmin}^{-1}$ flow rate. The inlet water temperature was set to $2^{\circ} \mathrm{C}$ for the heat exchanger modeling. The test data show that the computational fluid dynamics simulations are within a few degrees Celsius of the measured flow temperatures. The steady-state temperature rise of the water was $10^{\circ} \mathrm{C}$ and the PV power conversion cells can operate at $>100^{\circ} \mathrm{C}$.

For case A simulations, the peak steady-state end-face temperature rose to $39^{\circ} \mathrm{C}$ and the side-wall temperature rose to $10^{\circ} \mathrm{C}$. For case $\mathrm{B}$ (pump failure at full laser power), peak side-wall temperature reached $29^{\circ} \mathrm{C}$; in case $\mathrm{C}$ (recirculation mode), peak side-wall temperature is $<25^{\circ} \mathrm{C}$. From these simulations we conclude that, in all conditions, heat transfer through the side walls of the beam dump is satisfactorily efficient. Further, simulation results show that temperatures within the dump do not approach the service limits of internal materials or electrical components. Of these, the PV cells are the most sensitive; they are rated for service at temperatures up to $125^{\circ} \mathrm{C}$, but performance declines with increasing temperature. We have therefore set a maximum acceptable temperature of $70^{\circ} \mathrm{C}$ for the inside of the beam dump to provide a margin of safety and ensure good PV cell efficiency.

\section{Sample return and future project phases}

Ultimately, VALKYRIE is intended as a viable alternative to deep drilling for a clean deep sample return mission. Owing

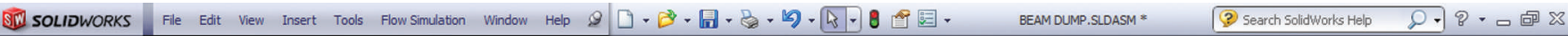

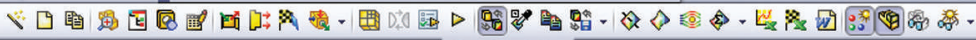

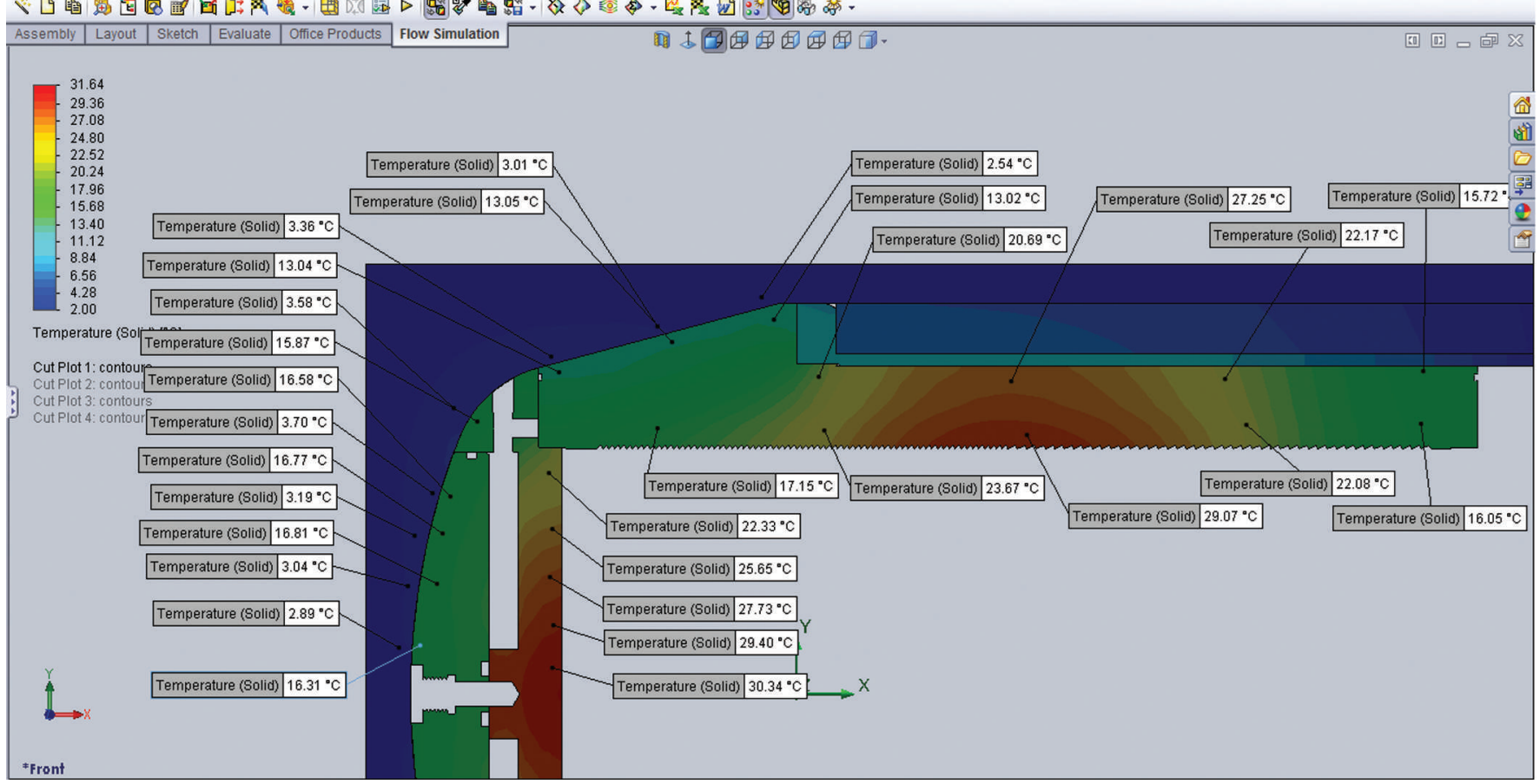

Fig. 26. Steady-state beam dump temperatures at $5 \mathrm{~kW}$ and failed water jet pumps. 


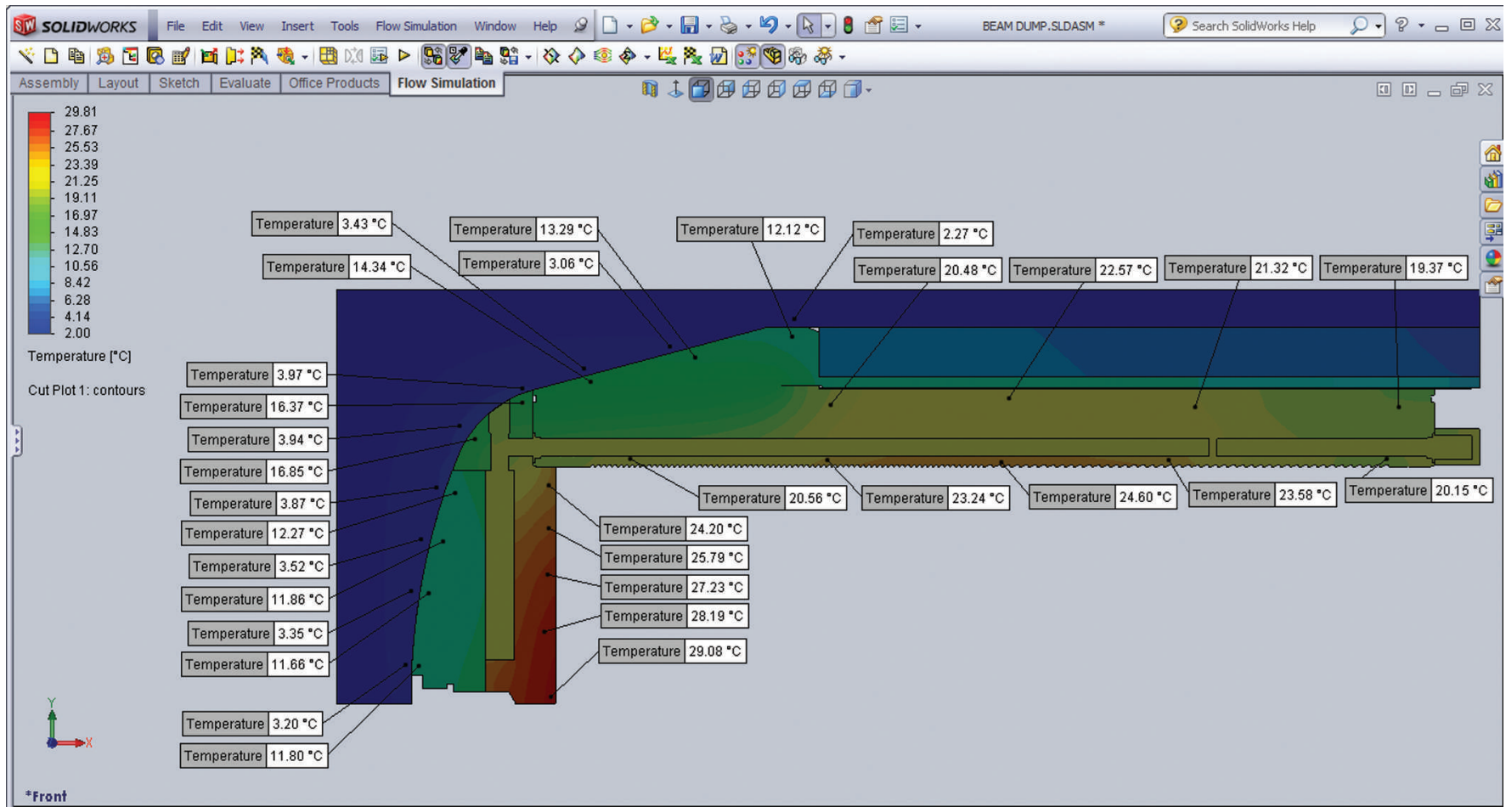

Fig. 27. Steady-state beam dump temperatures at $5 \mathrm{~kW}$ with internal recycling of water.

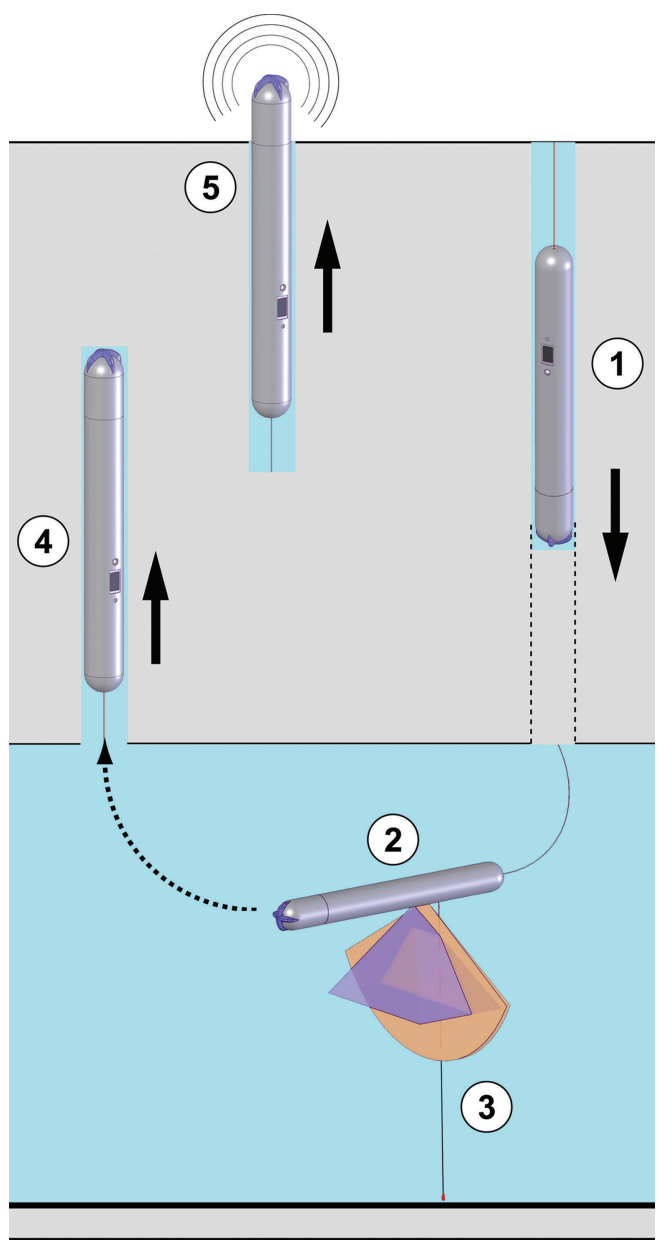

Fig. 28. Envisioned subglacial lake sample return mission: (1) descent through the ice cap; (2) vehicle pitch-up maneuver and conversion to AUV; (3) bottom sample acquisition and bathymetric mapping; (4) vehicle pitch-up maneuver with center of gravity shifting and buoyancy increase; and (5) return to surface. to limitations of funding we have broken the project into several phases, beginning with the issue posing the largest technical risk: is it possible to pump large quantities of photons down an optical waveguide and then use them to do something useful at the other end? In this paper, we have presented the results of our work in this area thus far, with the full intention of addressing the more refined challenge of sample return in subsequent research and development. VALKYRIE is being designed as an extension of AUV technology developed at Stone Aerospace. As such, buoyancy control and attitude control are common engineering requirements we deal with. The present end-to-end VALKYRIE mission scenario we are ultimately working towards (Fig. 28) is as follows:

an autonomous descent vehicle will breach the roof of a subglacial lake;

a conversion process will then begin in which the vehicle performs a $90^{\circ}$ pitch-up maneuver to function as an AUV for as much as $1 \mathrm{~km}$ of horizontal investigation from the melt hole;

the vehicle will collect both water and sediment samples in the subglacial lake;

an inversion system will then be activated that causes the vehicle to perform another $90^{\circ}$ pitch-up maneuver;

a buoyancy engine will activate and cause the vehicle to rise up through the ice cap.

The final two maneuvers will be accomplished through the use of center-of-gravity shifters and either an actively operated buoyancy engine or a drop-mass release. In either event, the vehicle will rise up through the ice at approximately the same rate of descent, effectively rising buoyantly in an ice-bound body of water. In glaciers without a firn layer, the vehicle should be able to reach the surface 
directly; in ice masses covered by firn a small hot-water drill will be needed for recovery in the final $80-100 \mathrm{~m}$. The SAR in the vehicle nose will serve as a localizer beacon for recovery of the vehicle. Since there is no requirement for the vehicle to surface at the point of entry into the glacier, ice stratigraphy data can be acquired for two completely separate penetration lines through the glacier.

Field-testing of the phase 2 vehicle design will take place on Matanuska Glacier, Alaska, USA, in 2014 and 2015. This is a polythermal glacier and, to the depth extent of the test missions planned for phase 2, the melt hole will not refreeze during the tests, allowing vehicle retrieval via stainless-steel cable.

\section{CONCLUSIONS}

We have developed a working prototype for a cryobot that receives its power from a high-energy laser beam channeled into an optical waveguide that is stored on, and released by, the cryobot as it descends through an ice cap. The laser beam is expanded into a beam dump where the majority of the heat content is extracted through an efficient microchannel heat exchanger, which is provisioned by meltwater generated in front of the beam dump. Additional thermal power is extracted from a subsidiary heat exchanger controlling the temperature of the on-board fiber spooler. Both heat sources are used to heat incoming water, which is routed through hot-water jets on the vehicle's nose. The jets can be selectively powered to produce forward and diverting trajectories. Lateral jets can also be used to turbulently remove released sediment. A portion of the beam impinges on a multistage high-temperature PV array, which generates electrical power to run all vehicle pumps and electronics directly. A reserve battery is used to start up the on-board control system prior to laser power-up.

We expect to conduct field tests of the basic vehicle, with science payload elements (a deep-ultraviolet flow cytometer for fluorescence-based microbe detection and water and filter sample collection systems, to be discussed in subsequent papers), on Matanuska Glacier beginning May 2014. The field tests will be conducted using a $5 \mathrm{~kW}$ $1070 \mathrm{~nm}$ fiber laser powered by a $30 \mathrm{~kW}$ diesel generator.

The theoretical basis for this significant departure from traditional ice-penetrating technology has been validated through laboratory testing by our team at power levels up to $11 \mathrm{~kW}$. The limitations of that test (failure at a fiber junction) have been addressed, and it is our opinion that transmission of power levels an order of magnitude higher should be achievable within this decade. At such levels, an autonomous entry into a subglacial lake (e.g. Vostok Subglacial Lake, East Antarctica) could be achieved with a penetration time of 1 week.

Importantly, VALKYRIE is a self-contained autonomous system. Although high-bandwidth communications can be maintained with the vehicle, either by modulating a separate signal on the laser fiber or by trailing a separate smaller telcom fiber, it is important to recognize that this glass thread will be frozen in the descent path as it is spooled out from the vehicle. Forward contamination of a subglacial lake can thus be prevented by controlled decontamination of the vehicle to accepted planetary protection levels in a laboratory environment prior to the mission, and transport to the test site in a sterile transport mechanism. A sterile insertion mechanism will start the vehicle on its downward journey into the ice cap; the vehicle will subsequently travel in its own void, which will refreeze behind the descent path. This methodology will reduce surface supply logistics requirements to that of the laser and its thermal regulation equipment, a diesel generator, fuel and crew support.

\section{ACKNOWLEDGEMENTS}

VALKYRIE is a NASA-sponsored research activity, funded through the ASTEP (Astrobiology Science and Technology for Exploring Planets) program office, NASA Science Directorate, under grant NNX11AJ89G. The team would like to thank Mary Voytek at NASA Headquarters for her vision, support and guidance throughout the project.

\section{REFERENCES}

Boechat AAP, Su D, Hall DR and Jones JD (1991) Bend loss in large core multimode optical fiber beam delivery systems. Appl. Opt., 30(3), 321-327 (doi: 10.1364/AO.30.000321)

Engelhardt H, Kamb B and Bolsey R (2000) A hot-water icecoring drill. J. Glaciol., 46(153), 341-345 (doi: 10.3189/ 172756500781832873)

Farrow RL, Kliner DAV, Hadley GR and Smith AV (2006) Peakpower limits on fiber amplifiers imposed by self-focusing. Opt. Lett., 31(23), 3423-3425 (doi: 10.1364/OL.31.003423)

Ghatak AK and Thyagarajan K (1998) Introduction to fiber optics. Cambridge University Press, Cambridge

Gulati S and 8 others (2010) Toward autonomous scientific exploration of ice-covered lakes - field experiments with the ENDURANCE AUV in an Antarctic dry valley. In Proceedings of 2010 IEEE Conference on Robotics and Automation (ICRA), 3-7 May 2010, Anchorage, Alaska, USA. Institute of Electrical and Electronics Engineers, Piscataway, NJ, 308-315

Philberth K (1962) Une méthode pour mesurer les températures à l'intérieur d'un Inlandsis. C. R. Séances Acad. Sci. (Paris), 254(22), 3881-3883

Stone W, Fairfield N and Kantor GA (2007) Masterclass in AUV technology for polar science: collaborative Autosub science in extreme environments. In Proceedings of the International Masterclass, 28-30 March 2006, Southampton, UK. National Oceanography Centre, Southampton

Stone W and 11 others (2010) Design and deployment of a fourdegrees-of-freedom hovering autonomous underwater vehicle for sub-ice exploration and mapping. J. Eng. Marit. Environ. 224(4), 341-361 (doi: 10.1243/14750902JEME214)

Zimmerman W, Bonitz R and Feldman J (2001) Cryobot: an icepenetrating robotic vehicle for Mars and Europa. In Proceedings of the 2001 IEEE Aerospace Conference, 8-15 March 2001, Big Sky, MT, USA. Institute of Electrical and Electronics Engineers, Big Sky, MT. CD-ROM 